\title{
Volatile Compounds in "Alvaich" Bread Produced by Milk Starter Cultural and Saccharomyces cerevisiae
}

Soumia M Darwish ${ }^{1 *}$ and Al-Zahraa M Darwish ${ }^{2}$

${ }^{1}$ Department of Food Science and Technology, Faculty of Agriculture, Assiut University, Egypt

${ }^{2}$ Department of Dairy Science, Faculty of Agriculture, Assiut University, Egypt

\begin{abstract}
Alvaich bread is manufactured in the Egyptian countryside according to a specific method of fermentation and is produced commercially using Saccharomyces cerevisiae. Alvaich sourdough is prepared in the countryside using a starter known as milk starter culture. The aim of this study was to evaluate the effect of the fermentation method on the volatile compounds that can affect the organoleptic characteristics of the aroma of Alvaich bread produced using milk starter culture and $S$. cerevisiae. The volatile compounds in the Alvaich breads were analyzed by gas chromatography/mass spectrometry (GC/MS). Four esters, one acid, one alcohol, one thiazole and one ketone were detected in Alvaich bread produced using milk starter culture (ABPMSC). Three esters, three acids and two furans were detected in Alvaich bread produced using S. cerevisiae (ABPS). Thiazole compounds with antibicrobial activity were detected in (ABPMSC), especially 4-(4-nitrophenyl)-2-(3-phenyl-2-propenylthio)-thiazole 7.906 \pm 0.54 . There are statistically significant differences $(p<0.05)$ between $(A B P M S C)$ and (ABPS) bread with regard to aroma, taste and overall quality.
\end{abstract}

Keywords: Alvaich; Bread; Milk fermentation; Saccharomyces cerevisiae; Volatile compounds

\section{Introduction}

Since ancient times, traditional foods have been passed down from one generation to another over the years. They have become a part of the cultural and traditional base among the native communities in most developing countries, especially in Africa. Traditional foods have characteristics related to the location, specific ingredients and methods of production available to native peoples [1-4]. In earlier times, sourdough was used in bread-making, while in the last century, it has been substituted by baker's yeast (Saccharomyces cerevisiae) [57]. Lactic acid bacteria (LAB) were used in ancient traditional food technology, especially cereal fermentations [8-11]. The mildly sour taste in fermented food comes from lactic acid, which is produced using Lactobacilli [10]. There is a special traditional type of bread baked in Egypt, called Alvaich bread (AB), that has employed this form of technology since ancient times. The sourdough variety of original $\mathrm{AB}$ is fermented using the curd of a fermented milk starter culture that is prepared by a very special method in the villages. This is a form of food preservation technology that has been used since ancient times. In contrast, $\mathrm{AB}$ is produced commercially using yeast (Saccharomyces cerevisiae). Alvaich bread produced using a milk starter culture has unique organoleptic properties that may be a result of the fermentation method. Traditional Alvaich bread fermentation is a form of food processing in which microbes such as lactic acid bacteria (LAB) are utilized. The most important factors contributing to bread quality are the loaf volume texture, color, and flavor. The characteristic aroma of bread is the one of the most important parameters influencing consumer acceptance [12-15]. Flavour is in the mind. It may be caused by numerous components, many of which have very distinct olfactory characteristics. In bread, the volatile and nonvolatile compounds that contribute to flavor include acids, alcohols, aldehydes, ethers, furans, hydrocarbons, ketones, lactones, pyrazines, pyrroles and sulfur compounds [15]. More than 540 of these compounds can be found in bread [16]. The major volatile components of the bread are alcohols, especially ethanol, isobutanol, and 3-methyl-butanol. Additionally, carbonyl compounds such as 3-methyl butanal, 2,3-butanedione, and hexanal are important but do not necessarily make major contributions to the flavor quality of the bread [16-20]. In this study, four types of Alvaich bread were produced: the first three types were produced using fermented milk starter culture (the three traditional methods), the fourth one was produced using the yeast "Saccharomyces cerevisiae". Type with the best result on sensory evaluation scale from the first three types was compared with the fourth one. The aim of this study was to evaluate the effect of the fermentation method on the volatile compounds that can affect the organoleptic characteristics of Alvaich bread.

\section{Materials and Methods}

\section{Materials}

Wheat flours ( $72 \%$ and $82 \%$ extraction) were obtained from the Middle Egypt Flour Mill Company, Egypt. Buffalo milk purchased from dairy farm in Assiut, Egypt. Peas (Cicer ariethinum) and sesame seeds (Sesamum indicum), dry active yeast (Saccharomyces cerevisiae, S.I. Lesaffre, France), margarine and salt, were purchased from local market in Assiut, Egypt.

\section{Alvaich sourdough production using milk starter culture}

Prepare the milk starter culture by heating $3 \mathrm{~kg}$ of raw buffalo milk until point of boiling $\left(100^{\circ} \mathrm{C}\right)$. Divide the milk into three parts and place each part in jar, and prepare the three parts: $1 \mathrm{~kg}$ of buffalo raw milk (BRM), $1 \mathrm{~kg}$ of buffalo raw milk with $5 \mathrm{~g}$ of sesame seeds (BRMSS) and $1 \mathrm{~kg}$ of buffalo raw milk with $5 \mathrm{~g}$ of ground chickpeas (BRMCS). Put each jar of BRM, BRMSS and BRMCS in $2 \mathrm{~kg}$ of hot bran

*Corresponding author: Soumia M Darwish, Department of Food Science and Technology, Faculty of Agriculture, Assiut University, Egypt, Tel: +201112325374: E-mail: soumiadarwish123@hotmail.com

Received February 17, 2016; Accepted March 31, 2016; Published April 08, 2016

Citation: Darwish SM, Darwish AZM (2016) Volatile Compounds in "Alvaich" Bread Produced by Milk Starter Cultural and Saccharomyces cerevisiae. J Microb Biochem Technol 8: 183-187. doi: 10.4172/1948-5948.1000283

Copyright: (c) 2016 Darwish SM, et al. This is an open-access article distributed under the terms of the Creative Commons Attribution License, which permits unrestricted use, distribution, and reproduction in any medium, provided the original author and source are credited. 
$\left(90^{\circ} \mathrm{C}\right)$ and cover for approximately 24 hours in the summer or 48 hour in the winter. The milk starter culture will be ready when the milk has fermented to curd on the surface (milk starter culture) and whey on the bottom. Separate the curd from the whey and mix slowly with $1 \mathrm{~kg}$ of flour, $5 \mathrm{~g}$ of salt and warm water $\left(40^{\circ} \mathrm{C}\right)$ until it forms a dough, and then cover the mixing. Let the dough rise at room temperature until doubled in volume, which takes approximately one hour; at this point, it is called mother dough (I refreshment). In the clay pot, knead the mother dough with $5 \mathrm{~kg}$ of white flour, $1 \mathrm{~kg}$ of milk, $0.5 \mathrm{~kg}$ of margarine or margarine, why of milk starter cultural and warm water $\left(40^{\circ} \mathrm{C}\right)$. Let the dough sit at room temperature for approximately $2 \mathrm{~h}$ in the summer $\left(30-38^{\circ} \mathrm{C}\right)$ or $4 \mathrm{~h}$ in the winter $\left(12-25^{\circ} \mathrm{C}\right)$ to obtain risen dough (2refreshment). After that, divide the dough into pieces of approximately $125 \mathrm{~g}$ and shape the dough into rolls; then, roll the dough between the palms until round. Let it sit at room temperature for approximately $1 \mathrm{~h}$ during the summer $\left(30-38^{\circ} \mathrm{C}\right)$ and $2 \mathrm{~h}$ during the winter $\left(12-25^{\circ} \mathrm{C}\right)$ or until doubled in size. Bake Alvaich bread until it becomes golden brown, which takes approximately $15-20 \mathrm{~min}$ at $195^{\circ} \mathrm{C}$. The previous steps are repeated with BMS and BMC milk starter culture. The processes of sourdough starter production are shown as a flow chart in Figure 1.

\section{Alvaich sourdough production by Saccharomyces cerevisiae}

Using dry active "yeast cells" stir the yeast into the warm water $\left(40^{\circ} \mathrm{C}\right)$ and let it sit until dissolved. In the kneading bowl, whisk together the $5 \mathrm{~kg}$ of white flour, $1 \mathrm{~kg}$ of milk, $0.5 \mathrm{~kg}$ of margarine or margarine and warm water $\left(40^{\circ} \mathrm{C}\right)$. Add this to the yeast mixture and stir until combined. Add all of the flour and stir until it forms a shaggy dough. Let the dough sit at room temperature for approximately $1 \mathrm{~h}$ in the summer $\left(30-38^{\circ} \mathrm{C}\right)$ or $2 \mathrm{~h}$ in the winter $\left(12-25^{\circ} \mathrm{C}\right)$ to obtain risen dough. After that, divide the dough into pieces of approximately 125 $\mathrm{g}$ and shape the dough into rolls; then, roll the dough between the palms until round. Let it sit at room temperature for approximately 30 min during the summer $\left(30-38^{\circ} \mathrm{C}\right)$ or $1 \mathrm{~h}$ during the winter $\left(12-25^{\circ} \mathrm{C}\right)$ or until doubled in size. Bake Alvaich bread until it becomes golden brown, which takes approximately $15-20 \mathrm{~min}$ at $195^{\circ} \mathrm{C}$.

\section{Microbial count}

The samples for microbial counts were raw buffalo milk and three starter samples namely: buffalo raw milk before boiling (BRM), buffalo milk starter (BMS), buffalo milk starter with sesame seeds (BMSS) and buffalo milk starter with chickpeas seeds (BMCS). Raw buffalo milk was used to prepare the milk starter culture (BRM), and three starter samples, namely, BMS, BMSS and BMCS (the most frequently three starters used in Alvaich bread fermentation in the countryside), were analyzed for total microbial count, lactic acid bacteria, yeast and E. coli. One gram of sample was 10 -fold diluted with $9 \mathrm{~g} / \mathrm{L} \mathrm{NaCl}$ solution and plated onto selective media.

Counting of bacteria: The standard plate count technique was used to count the bacterial content of the starter samples. Appropriate dilutions of 1-g starter samples of BRM, BMS, BMSS and BMCS were diluted with $9 \mathrm{~g} / \mathrm{L} \mathrm{NaCl}$ solution and plated onto agar medium, which has the following composition: $3.0 \mathrm{~g}$ of bacto-yeast extract, $3.0 \mathrm{~g}$ of beef extract, $5.0 \mathrm{~g}$ of bacto-peptone, $2.5 \mathrm{~g}$ of glucose, $2.5 \mathrm{~g}$ of lactose, $5.0 \mathrm{~g}$ of sodium chloride, $18.0 \mathrm{~g}$ of agar and $1000 \mathrm{ml}$ of distilled water. The $\mathrm{pH}$ of the medium was adjusted to 7.0 , and the medium was sterilized. The plated medium was incubated at $30^{\circ} \mathrm{C}$ for $72 \mathrm{hrs}$ (an optimal growth of bacteria from of BRM, BMS, BMSS, BMCS after incubated the cultures for $72 \mathrm{hrs}$ and that may be due to the type of bacteria), at the end of which the numbers of colonies were determined. After plate counts were obtained, averages were calculated. The microbial counts are reported as $\log \mathrm{cfu} / \mathrm{g}$.
Isolation and identification of bacteria: Twenty to 25 colonies were selected from either duplicated or opposite sectors of the same plate, and transferred to tubes containing sterilized litmus milk. The tubes were incubated at $30^{\circ} \mathrm{C}$, and the reaction progress was recorded daily for 14 days. Tubes showing the reaction were placed in the refrigerator until an inoculum was transferred to a slope medium. The color of the colony on the medium was noted. Morphological examinations were carried out using Gram staining according to a previously described method [21]. Identification of the bacterial isolates was carried out according to the work of Ray and Sandine [22].

Isolation of Lactic acid bacteria: Dilutions of $1 \mathrm{~g}$ of BRM and starter samples (BMS, BMSS and BMCS) with $9 \mathrm{~g} / \mathrm{L} \mathrm{NaCl}$ solution were prepared and plated onto MRS media with the following composition: $10.0 \mathrm{~g}$ of peptone, $10.0 \mathrm{~g}$ of beef extract, $5.0 \mathrm{~g}$ of yeast extract, $20.0 \mathrm{~g}$ of dextrose, $1.0 \mathrm{ml}$ of Tween $80,2.0 \mathrm{~g}$ of ammonium citrate, $5.0 \mathrm{~g}$ of sodium acetate, $0.05 \mathrm{~g}$ of manganese sulfate, $0.1 \mathrm{~g}$ of magnesium sulfate, $2.0 \mathrm{~g}$ of potassium phosphate dibasic and 1 liter of water.

\section{Headspace Solid-Phase Microextraction (HS-SPME)}

The samples for gas chromatography-mass spectrometry (GCMS) were two bread samples namely: Alvaich bread produced using milk starter culture (ABPMSC) and Alvaich bread produced using Saccharomyces cerevisiae (ABPS).10 g of bread samples was mixed with $\mathrm{NaCl}\left(10 \mathrm{~mL}, 1 \mathrm{~g} \cdot \mathrm{mL}^{-1}\right)$ and shaken for $30 \mathrm{~s}$. Five grams of this mixture was placed in a $125 \mathrm{~mL}$ flask with a magnetic stirring bar and $5 \mu \mathrm{L}$ of internal standard and closed with cap. The flask was incubated for $60 \mathrm{~min}$ in a heated tray oven at $40^{\circ} \mathrm{C}$. An SPME fibre with two different coatings $\left(75 \mu \mathrm{m}\right.$ carboxen $^{\mathrm{TM}}$ /polydimethylsiloxane; CAR/ PDMS stablFlex ${ }^{\mathrm{TM}}$ ) (Supelco Co., Bellefonte, PA, USA) was inserted in the headspace of the vial for $10 \mathrm{~min}$ to collect the volatiles. The type of fibre used can often affect the selectivity of the extraction and by using a mixed type; good selectivity is obtained for nonpolar analyte as well as for polar analyte. After each extraction, the fibre was inserted into the GC injector port using a $0.75 \mathrm{~mm}$ i.d liner (in order to improve the GC resolution). Desorption time and temperature were $5 \mathrm{~min}$ and $250^{\circ} \mathrm{C}$ respectively. All experiments and sample measurements were carried out in triplicate and the average values were recorded.

\section{Gas chromatography-mass spectrometry (GC-MS) analysis}

A Hewlett-Packard (HP) system 7890A series gas chromatograph coupled with an HP model 5975B quadrupole mass spectrometer and a cross-linked 5\% phenyl methyl siloxane capillary column (DB-5MS, 30 $\mathrm{m} \times 0.25 \mathrm{~mm}$ i.d. $\times 0.25 \mu \mathrm{m}$ film thickness) was used. The GC operating conditions were as follows: initial temperature, $40^{\circ} \mathrm{C}$ ( $1 \mathrm{~min}$ hold $)$, increased at $20^{\circ} \mathrm{C} \mathrm{min}-1$ to $210^{\circ} \mathrm{C}$, and then increased at $1.5^{\circ} \mathrm{C}$ min- 1 to $215^{\circ} \mathrm{C}$ ( $4 \mathrm{~min}$ hold); injector temperature, $240^{\circ} \mathrm{C}$; carrier gas, helium (99.999\%), flow-rate, $1.3 \mathrm{ml}-1 \mathrm{~min}$; ion source temperature, $270^{\circ} \mathrm{C}$; operated in the split less mode; purge off time, $1 \mathrm{~min}$; injection volume, $1 \mu \mathrm{l}$. The MS operating conditions were as follows: solvent delay, $6 \mathrm{~min}$; electron-impact (EI) mode ionization voltage, $70 \mathrm{eV}$ using selected ion monitoring (SIM); dwell time for each ion, $100 \mathrm{~ms}$. Volatiles identification was performed in one of the two ways, depending on the availability of standard compounds. Identification was performed based on the comparison of the mass spectrum of a compound with a NIST05 library match and comparison of retention indices with that available in literature. In addition, the odor characteristic for an analyzed compound was compared with literature data and used in tentative identification. 


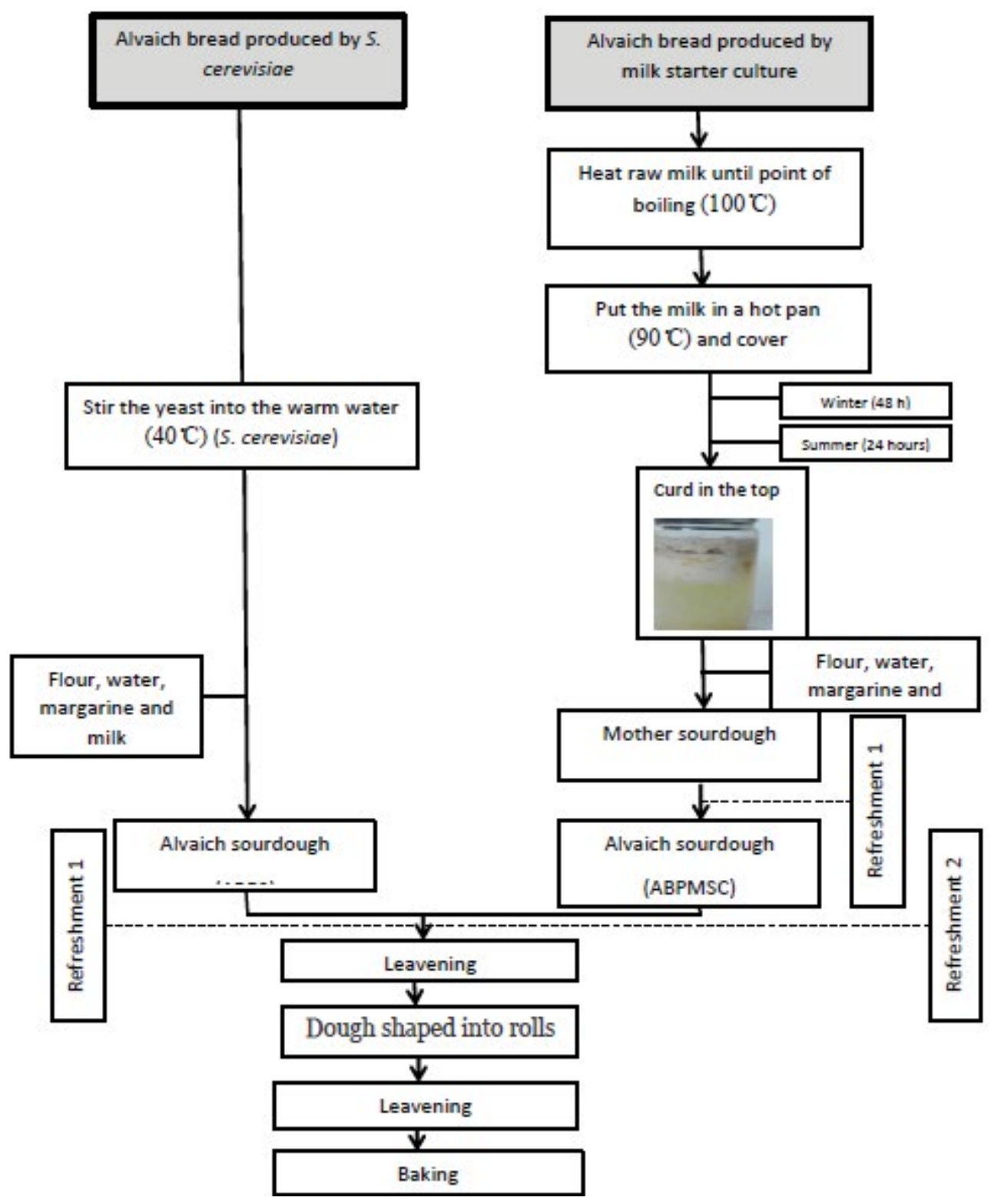

Figure 1: Flow chart of the Alvaich production. ABPMSC: Alvaich bread produced using milk 2 starter cultures; ABPS: Alvaich bread produced using S. cerevisiae.

\section{Sensory analysis}

The sensory evaluation of four types of Alvaich bread: the first three types were produced using fermented milk starter culture (BMS, BMSS and BMCS), the fourth one was produced using the yeast "Saccharomyces cerevisiae were determined using fifteen panelists (seven males and eight females, aged between 21 and 55 years) who have experience with bread and regularly used its descriptive vocabulary, participated. The Alvaich bread and traditional bread samples were scored by the panelists according to a preference protocol including a scale from 0 (unacceptable) to 10 (excellent) [17]. Panel members were also instructed to report any defects or unpleasant flavor.

\section{Statistical analysis}

Means and standard deviations (SD) of data were calculated with SPSS (Version 9.0) statistical software. SPSS was used to perform one- way analysis of variance (ANOVA) and the least significant difference (LSD) test at a $95 \%$ confidence level $(\mathrm{p}<0.05)$ was also used to identify differences among sensory evaluations of Alvaich bread.

\section{Results and Discussion}

\section{Microbiological analyses}

The total microbiological counts of the buffalo raw milk and three sour dough starters (BMS, BMSS and BMCS) are shown in Table 1. Yeast was $1.05 \mathrm{log}$ CFU/g in the raw buffalo milk. The count of yeast cells appear only in BRM but not appear in BMS, BMSS and BMCS his may be due to the production of the metabolic end product of these bacteria, lactic acid, inhibits yeast growth and metabolism $[16,19]$. The $\mathrm{LAB}$ counts in the buffalo milk were lower than the LAB count of the sourdough starter (BMS, BMSS and BMCS). Conversely, the buffalo milk with a ground chickpea starter recorded the highest LAB count 
of all starters. These results confirm those reported for sourdoughs used for traditional bread in Greece, which used chickpea seeds as a leavening agent [12]. Table 1 shows that the E.coli was observed only in the raw buffalo milk ( $0.97 \log \mathrm{CFU} / \mathrm{g})$ but was not detected in the three milk starter cultures. Lactic acid is able to inhibit the growth of many types of food spoilage bacteria, including gram-negative species of the families Enterobacteriaceae and Pseudomonadaceae [1,22].

\section{Volatile composition}

The number of volatile and non-volatile compounds detected during fermentation and baking resulted in the complex chemical and enzymatic reactions. It is likely that such compounds contributed to the final flavor in the Alvaich bread [14]. Categorize the volatile compounds of bread into bases, carbonyls- aldehydes, carbonyls- ketones, furans, esters, acids, alcohols, sulfur compounds, hydrocarbons, esters, lactones, phenols, acetals, epoxides and nitriles. In our study, the volatile compounds identified in Alvaich bread produced using milk starter cultures (Table 2). The volatile compounds present in Alvaich bread produced using Saccharomyces cerevisiae (Table 3). A possible explanation for why we detect different component in Alvaich bread produced using milk starter culture and Saccharomyces cerevisiae is the bread fermentation time. Brummer and Lorenz reported that fermenting the milk starter for a longer time gives the bread a stronger flavor [2]. For example, a leavening time up to $9 \mathrm{~h}$ increased the production of volatile compounds to approximately three times higher than that at $5 \mathrm{~h}$ as a result of the LAB contribution [23,24]. In our study, the bread fermentation time was much longer in Alvaich bread produced using milk starter culture than in bread fermented by Saccharomyces cerevisiae. Some differences were noticed between Alvaich bread produced using milk starter cultures and that produced using Saccharomyces cerevisiae. Acids, ketones and thiazole compounds were detected in Alvaich breads including ethyl p-tert-butyl benzoic acid, 4,5-dihydroxy-octa-3,5diene-2,7-dione and 4-(4-nitrophenyl)-2-(3-phenyl-2-propenylthio)thiazole, respectively. The lactic fermentation of cereals improved the flavor, enhanced the nutritional value and shelf life and increased the food quality of the bread by removing toxic or antinutritional factors of food products [23-25]. High levels of alcohol compounds were detected in the Alvaich bread produced using Saccharomyces cerevisiae, especially 2-methoxy-.alpha.-methyl-cyclohexaneethanol, 2-methyl-3buten-2-ol and cyclobutanol; esters, especially 5-chloro-2-methyl-1(trimethylsilyl)-1H-indole-3-acetic acid trimethylsilyl ester, hexanoic acid heptadecyl ester and 7-oxo-octanoic acid trimethylsilyl ester, were also detected (Table 3). Furans are volatile aromatic compounds that form in the heat exchange processes of food production and baking [20]. Furan compounds were detected in the Alvaich bread produced using Saccharomyces cerevisiae only, especially 3-(1-fluoroethyl)-5-(2-[2-(3hydroxypropyl) phenyl] ethyl) dihydro- $2(3 \mathrm{H})$-furanone and dihydro5-propyl-2(3H)-furanone (Table 3). Colombo-Corti and MarazziUberti [7] observed antibacterial activity of thiazole compounds such as 2-acetamido-4-(5-nitro-2-furyl) thiazole (Furium), which has activity against Staphylococcus aureus, Salmonella typhimurium and other pathogenic enterobacteria. Thiazole compounds were detected only in Alvaich bread produced using milk starter cultures $7.906 \pm 0.54$, especially4-(4-nitrophenyl)-2-(3-phenyl-2-propenylthio)-thiazole.

\section{Sensory evaluation of breads}

The sensory evaluation showed appreciable differences between Alvaich bread produced using milk starter cultures (BMS, BMSS and BMCS) and Saccharomyces cerevisiae (Table 4). The best scores were recorded for Alvaich bread that was produced using milk starter culture (BMS), while the lowest results were obtained for the Alvaich bread produced using Saccharomyces cerevisiae. Statistically, there were significant

\begin{tabular}{|l|c|c|c|c|}
\hline Samples & T.C & LAB & Yeast & E.coli \\
\hline & $\log \mathrm{cfu} / \mathrm{g}$ & $\log \mathrm{cfu} / \mathrm{g}$ & $\log \mathrm{cfu} / \mathrm{g}$ & $\log \mathrm{cfu} / \mathrm{g}$ \\
\hline BRM & 3.956 & 1.930 & 1.050 & 0.970 \\
\hline BMS & 4.008 & 4.000 & - & - \\
\hline BMSS & 4.309 & 4.300 & - & - \\
\hline BMCS & 5.116 & 5.110 & - & - \\
\hline
\end{tabular}

BRM: raw buffalo milk; BMS: buffalo milk starter without any additives; BMSS: buffalo milk starter with sesame seeds; and BMC: buffalo milk starter with ground chickpeas.

Table 1: Microbial counts (total count, LAB, yeasts and E.coli) in buffalo raw milk (BRM)and three different starter cultures that were used in the fermentation of Alvaich bread( BMS, BMSS \& BMCS). The microbial counts (LAB, yeasts and E.coli) are calculated as log cfu/g.

\begin{tabular}{|l|c|}
\hline Volatile compounds & \\
\hline 4-Cyanobenzoic acid 2,6-dimethylnon-1-en-3-yn-5-yl ester & $2.170 \pm 0.11$ \\
\hline Anthranilic acid cinnamyl ester & $2.172 \pm 0.16$ \\
\hline 3-Oxo-butanethioic acid S-propyl ester & $2.749 \pm 0.01$ \\
\hline Hexanoic acid octadecyl ester & $1.789 \pm 0.26$ \\
\hline $\begin{array}{l}\text { 2-Methoxy-.alpha.-methyl-cyclohexane ethanol } \\
\text { Furans }\end{array}$ & $2.938 \pm 0.65$ \\
\hline Ethyl p-tert-butyl benzoic acid & - \\
\hline 4,5-Dihydroxy-octa-3,5-diene-2,7-dione & $2.134 \pm 0.26$ \\
\hline 4-(4-nitrophenyl)-2-(3-phenyl-2-propenylthio)-thiazole & $1.866 \pm 0.31$ \\
\hline
\end{tabular}

Table 2: Volatile compounds expressed as peak area \pm Standard Deviation in the Alvaich bread produced using milk starter culture.

\begin{tabular}{|l|c|}
\hline \multicolumn{1}{|c|}{ Compounds } & \\
\hline $\begin{array}{l}\text { 5-chloro-2-methyl-1-(trimethylsilyl)-1H-indole-3-acetic acid } \\
\text { trimethylsilyl ester }\end{array}$ & $2.054 \pm 0.12$ \\
\hline Hexanoic acid heptadecyl ester & $3.109 \pm 0.23$ \\
\hline 7-Oxo-octanoic acid trimethylsilyl ester & $4.849 \pm 0.68$ \\
\hline 2-Methoxy-alpha-methyl-cyclohexaneethanol & $3.459 \pm 0.25$ \\
\hline 2-Methyl-3-buten-2-ol & $1.410 \pm 0.20$ \\
\hline Cyclobutanol & $3.424 \pm 0.54$ \\
\hline $\begin{array}{l}\text { 3-(1-Fluoroethyl)-5-(2-[2-(3-hydroxypropyl)phenyl]ethyl)dihydro- } \\
\text { 2(3H)-furanone }\end{array}$ & $1.837 \pm 0.15$ \\
\hline Dihydro-5-propyl-2(3H)-furanone & $1.959 \pm 0.12$ \\
\hline Acids & - \\
\hline Ketones & - \\
\hline Thiazole & - \\
\hline
\end{tabular}

Table 3: Volatile compounds expressed as peak area \pm Standard Deviation in in Alvaich bread produced using Saccharomyces cerevisiae.

\begin{tabular}{|l|c|c|c|c|}
\hline \multirow{2}{*}{ Attributes } & \multicolumn{4}{|c|}{${ }^{*}$ Types of Alvaich bread produced using } \\
\cline { 2 - 5 } & BMS & BMSS & BMCS & S. cerevisiae \\
\hline Aroma & $9.66 \pm 0.48$ & $9.06 \pm 0.25$ & $6.20 \pm 0.86$ & $4.9 \pm 0.76$ \\
\hline Taste & $9.46 \pm 0.51$ & $8.80 \pm 0.56$ & $5.66 \pm 0.72$ & $4.8 \pm 0.56$ \\
\hline Overall quality & $9.4 \pm 0.50$ & $9.00 \pm 0.37$ & $5.60 \pm 0.63$ & $4.46 \pm 0.74$ \\
\hline
\end{tabular}

* Mean \pm SD with the same superscripts are not significantly $(p>0.05)$ different: milk starters cultures (BMS: buffalo milk starter; BMSS: buffalo milk starter with sesame seeds; BMC: buffalo milk starter with ground chickpeas) and Alvaich bread produced using $S$. cerevisiae

Table 4: Panelists' sensory evaluations of Alvaich bread produced using milk starter cultures (BMS, BMSS and BMCS) and S. cerevisiae.

differences $(p<0.05)$ in aroma, taste and overall quality between the Alvaich bread produced using milk starter cultures (BMS, BMSS and BMCS) and that produced using Saccharomyces cerevisiae. That was because the bread starters were different and the fermentation time was much longer for Alvaich bread produced using milk starter cultures. 
Citation: Darwish SM, Darwish AZM (2016) Volatile Compounds in "Alvaich" Bread Produced by Milk Starter Cultural and Saccharomyces cerevisiae. J Microb Biochem Technol 8: 183-187. doi: 10.4172/1948-5948.1000283

\section{Conclusions}

The content of volatile compounds in the Alvaich breads varied with the starter culture used. The volatile compounds in the Alvaich breads fermented using milk starter culture were classified as esters, acids, alcohols, thiazoles and ketones components. The volatile components present in Alvaich breads fermented using S. cerevisiae were classified as esters, acids and furans component. Thiazole compounds with antibicrobial activity were detected in (ABPMSC), especially 4-(4-nitrophenyl)-2-(3-phenyl-2-propenylthio)-thiazole $7.906 \pm 0.54$. The statistical analysis shows significant differences $(p<0.05)$ between ABPMSC and ABPS. The highest results for aroma, taste and overall quality were obtained for the ABPMSC. The volatile profile of ABPMS results in a stronger flavor that was affected by method of bread fermentation for a long period of time.

\section{Acknowledgments}

This research was financially supported by Assuit University, Egypt.

\section{References}

1. Alakomi HL, Skyttä E, Saarela M, Mattila-Sandholm T, Latva-Kala K, et al (2000) Lactic acid permeabilizes gram-negative bacteria by disrupting the outer membrane. Appl Environ Microbiol 66: 2001-2005.

2. Brummer JM, Lorenz K (1991) European developments in wheat sourdoughs. Cereal Foods World 36: 310-314.

3. Caul M (1972) La flaveur des aliments et le consommateur. Bull Anc Eleves Ec Meun ENSMIC 251: 242-246.

4. Cayot N (2007) Sensory quality of traditional foods. Food Chemistry 102: 445453.

5. Chalmers $\mathrm{CH}$ (1965) Bacteria in relation to the milk supply. Can J Comp Med Vet Sci 20: 96.

6. Chang CY, Seitz LM, Chambers E (1995) Volatile flavor components of breads made from hard red winter-wheat and hard white winter-wheat. Cereal Chemistry 72 : 237-242.

7. Colombo-Corti I, Marazzi- Uberti E (1962) Sull "attivita" antimicrobica in vitro del 2-acetamido-4-(5-nitro-2-furil) tiazolo. BollSocltal Biol Sper 38: 1432-1436.

8. El-Gendy SM (1983) Fermented foods of Egypt and the Middle East. Journal of Food Protection 46: 358-367.

9. Gobbetti M, De Angelis M, Corsetti A, Di Cagno R (2005) Biochemistry and physiology of sourdough lactic acid bacteria. Trends in Food Science \& Technology 16: 57-69.
10. Hansen AS (2011) Sourdough bread, plant-based fermented food and beverage technology. Boca Raton 9: 495-515.

11. Hansen EB (2002) Commercial bacterial starter cultures for fermented foods of the future. Int J Food Microbiol 78: 119-131.

12. Hatzikamari $M$, Kyriakidis DA, Tzanetakis $N$, Biliaderis CG, LitopoulouTzanetaki E (2007) Biochemical changes during a submerged chickpea fermentation used as a leavening agent for bread production. European Food Research and Technology 224: 715-723.

13. Lund B, Hansen A, Lewis MJ (1989) The influence of dough yield on acidification and production of volatiles in sourdoughs. Lebensmittel-Wissenschaft \& Technologie 22: 150-153.

14. Maarse H, Visscher C (1989) Volatile Compounds in Food-Qualitative and Quantitative data: TNOCIVO Food Analysis Institute, Netherlands.

15. Maga JA (1974) Bread flavor. CRC Crit Rev Food Technol 5: 55-142.

16. Maiorella B, Blanch HW, Wilke CR (1983) By-product inhibition Effects on ethanolic fermentation by saccharomyces cerevisiae. Biotechnology and bioengineering 25: 103-121.

17. Martens H, Naes T (1989) Multivariate calibration. Wiley, Chichester, UK.

18. Methods MoM (1957) Society of American Bacteriologists. McGraw-Hill Book Company, New York, Toronto, London.

19. Narendranath NV, Hynes SH, Thomas KC, Ingledew WM (1997) Effects of lactobacilli on yeast-catalyzed ethanol fermentations. Appl Environ Microbiol 63: 4158-4163.

20. Ozolina V, Kunkulberga D, Cieslak B, Obiedzinski M (2011) Furan derivatives dynamic in rye bread processing. Procedia Food Science 1: 1158-1164.

21. Pozo-Bayón M, Guichard E, Cayot N (2006) Flavor control in baked cereal products. Food Reviews International 22: 335-379.

22. Ray B, Sandine WE (1992) Acetic, propionic, and lactic acids of starter culture bacteria as biopreservatives. CRC Press, Boca Raton, Finland.

23. Rollán G, Gerez C, Dallagnol A, Torino M, Font G (2010) Update in bread fermentation by lactic acid bacteria. Current Research, Technology and Education Topics in Applied Microbiology and Microbial Biotechnology 8: 11681174.

24. Salimur R, Paterson A, Piggott JR (2006) Flavour in sourdough breads: a review. Trends in Food Science \& Technology 17: 557-566.

25. Schieberle P (1996) Intense aroma compounds: Useful tools to monitor the influence of processing and storage on bread aroma. Advances in food sciences 18: 237-244. 